

\section{Summary of findings}

(continued)

- Nearly 4 in 10 children have had contact with someone on the internet they had not met face-to-face before.

- $10 \%$ of all children have met someone in person that they first got to know online. This was higher for boys and older children (12-17 years-old).

- Just over 1 in 10 children have had virus or spyware on their digital device. This was more common among boys and teens aged 15-17 years old.

- In regard to teenagers' (13-17 year olds) perceptions of issues related to excessive internet use we found that, for example:

- $14 \%$ said they have experienced conflicts with family or friends because of the time they spent on the internet

○ $13 \%$ indicated having unsuccessfully tried to spend less time online

- $10 \%$ considered that the amount of time they spend on the internet is causing problems for them

- $9 \%$ reported to have gone without eating or sleeping

- $8 \%$ said they were getting lower marks at school due to excessive internet use.

New Zealand context. Further, by applying the Global Kids Online methodology these research-based insights can be compared with international experiences.

Netsafe uses this information to improve and develop our online safety prevention and support activities, contributing to our efforts to maximise digital opportunities for $\mathrm{New}$ Zealand's youngest internet users and prevent online harm. The findings in this report will also be of interest to whānau and parents, educators, government agencies, online content and service providers, and the research community. We hope the findings will contribute to the development of policies, practices and services designed to support New Zealand children to safely take advantage of the opportunities available to them online.

\section{What we know so far}

While children's experiences of online risks and harm is a growing area of research in New Zealand, public discussion on the matter has largely been informed by mainstream media's fixation on the dangers of technology (Pacheco \& Melhuish, 2018d). At best, debate on risks online has relied on overseas evidence. However, insights reflecting the New Zealand context and based on representative data are still needed to guide policy discussion, create awareness, and inform the implementation of prevention and support programmes for children. Clearly, the need for reliable and robust evidence is critical as online aggression and abuse not only can increase children's social isolation and emotional distress, among other negative impacts, but also, in some cases, trigger aggression against peers (Smith et al., 2008; Ybarra, Mitchell, \& Korchmaros, 2011).

Early New Zealand-based research on online risks and safety has focused on teenagers in the context of peer-to-peer victimisation, particularly cyberbullying (Pacheco \& Melhuish, 2018d). One study found that technologymediated harassment is more likely to occur between school peers and that cyberbullying via mobile phones was more common and likely to cause distress than using other internetbased tools (Fenaughty \& Harré, 2013). Evidence also suggests that teens' experience of traditional bullying is more likely to last longer than being the subject of cyberbullying (Jose, Kljakovic, Scheib, \& Notter, 2012) and that textbased bullying was linked with other forms of traditional bullying and harassment (Marsh, McGee, Nada-Raja, \& Williams, 2010).

Gender differences have also been part of the analysis of children's online risks and perceived harm in New Zealand. Recent Netsafe studies compare the different ways boys and girls use digital devices to connect to the internet, the activities they participate in online, and their preferences for specific social media platforms (Pacheco \& Melhuish, 2018b, 2019). Evidence suggests that a similar trend of gender differences can also be found in children's experiences of online risks and harm. Some 
studies show that cyberbullying and other forms of online harassment are not only more common among girls compared to boys (Fenaughty \& Harré, 2013; Pacheco \& Melhuish, 2018d; Steiner-Fox et al., 2016) but also more likely to cause them emotional distress and negatively affect their daily activities such as being able to interact with family and friends (Pacheco \& Melhuish, 2018d). However, while for girls it is more common to be the target of online aggression, evidence also suggests that they are more likely to engage in hurtful online behaviours against their peers (Green, Harcourt, Mattioni, \& Prior, 2013).

As children are finding creative ways to use and interact through technology, and digital tools continue to develop, new forms of risky and potentially harmful behaviours (and opportunities) are likely to emerge. In this respect, Netsafe's research programme has sought to identify and/or explore some of these new or risky behaviours. For instance, we have reported on teenagers' sending, receiving, and requesting nude or nearly nude images or videos through digital technology, a behaviour commonly known as 'sexting'. The study found that while only $4 \%$ of New Zealand teens had shared a nude picture or video of themselves in the last 12 months, nearly 1 in 5 has been asked for this sort of content, with girls being significantly more likely to be asked for nudes of themselves (Pacheco \& Melhuish, 2017).

Another Netsafe study asked teens whether they have anonymously posted or shared mean or negative online content about themselves. Findings about the prevalence of this online behaviour, also known as digital self-harm, show that a small number of teens (6\%) did engage in this activity in the prior year, that it was more prevalent among younger teenagers ( 13 and 14 years old), and that the overall purpose was to seek others' attention - some of the main reasons reported by teens included: making a joke, wanting to show resilience, looking for friends' sympathy, and/or seeking reassurance of friendship among other reasons (Pacheco, Melhuish, \& Fiske, 2019). Findings from another New Zealand-based study suggest that teens who receive hurtful online content are likely to report more self-harm later (Jose \& Fu, 2018). In short, children will continue to engage with digital devices, which also will continue to evolve and become more sophisticated. Thus, it is the role of researchers and policy analysts to explore and understand the new ways kids adapt and interact through these tools, so children will be able to enjoy the affordances of technology in a safer way.

In addition, while New Zealand-based research on online risks and harm is increasing, there are still gaps in the understanding of the complexities of children's hurtful online experiences. For instance, we still lack understanding of the link between age and the prevalence of risks and abuse online, and what the longitudinal trends are regarding different forms of online aggression. Evidence about children's online experiences and/or exposure to problematic content such as hateful speech, violence, and drug-taking content, among others, is lacking too. We also need evidence about disadvantaged or vulnerable groups' experiences of online harassment and abuse. However, while researchers and academics seek to close these knowledge gaps regarding kids' online risks and safety, we also need a balanced reflection that takes into account not only the risks that technology poses but also children's agency and rights to access, information, privacy, and participation (Livingstone, Carr, \& Byrne, 2016).

\section{What we did}

The findings presented in this report are based on data from 2,061 New Zealand children aged 9-17. The weighted sample is representative of the population of New Zealand children with a maximum margin of error of $+/-2.2 \%$ for the whole population'. Fieldwork was administered by Colmar Brunton between 20 July and 30 September 2018. In Table 1 we present further details about the demographics of the sample in relation to gender, ethnicity and age.

$1+/-6.2 \%$ maximum error for each year of age, and +/-4.0\% for each age group: 9-11, 12-14 and 15-17-year-olds. 
Table 1. Ngā taiohi matihiko o Aotearoa - New Zealand Kids Online sample profile - children

\begin{tabular}{|c|c|c|}
\hline $\begin{array}{l}\text { Sub-population } \\
\text { (children) }\end{array}$ & $\begin{array}{l}\text { Weighted } \\
\text { sample size }\end{array}$ & $\%$ \\
\hline Boys & 1,057 & $51 \%$ \\
\hline Girls & 1,004 & $49 \%$ \\
\hline NZ European/Pākehā & 1,469 & $73 \%$ \\
\hline Māori & 521 & $26 \%$ \\
\hline Pacific & 265 & $13 \%$ \\
\hline Asian & 292 & $15 \%$ \\
\hline Other ethnicities & 48 & $2 \%$ \\
\hline 9 years old & 231 & $11 \%$ \\
\hline 10 years old & 255 & $12 \%$ \\
\hline 11 years old & 249 & $12 \%$ \\
\hline 12 years old & 209 & $10 \%$ \\
\hline 13 years old & 275 & $13 \%$ \\
\hline 14 years old & 167 & $8 \%$ \\
\hline 15 years old & 194 & $9 \%$ \\
\hline 16 years old & 247 & $12 \%$ \\
\hline 17 years old & 234 & $11 \%$ \\
\hline
\end{tabular}

Parental permission was obtained for all children who participated in the study. Parents were provided with full information about the purpose of the research project, and how research data from their child will be used. Both parents and children were introduced to the survey and the topics included in the questionnaire. Participating children were also informed about their rights to confidentiality and to withdraw their participation at any stage including after they had completed the survey.

Note that questions regarding exposure to potentially harmful online content and excessive internet use were asked only of teenagers aged 13 to 17 years due to the sensitive nature of the questions.
Netsafe is an active member of the Global Kids Online network. We used its research resources and applied its quantitative approach to collect robust and reliable data from New Zealand children. We also adapted its modular survey to the online environment. In this sense, data for our project was collected through an online survey, which was around 20 minutes in length. Converting the survey to the online environment has some practical benefits. In the last few years Netsafe has been using online surveys as part of its research programme as they reduce fieldwork costs, make data collection easier, facilitate storage and handling of research data, and help to increase response rates.

In this report we only present findings regarding children's experiences of online risks and their perceptions of harm which are part of Module $F$ of the Global Kids Online survey ${ }^{2}$. Module F includes questions related to children meeting a stranger, being bothered by something online, experiences of and engagement with hurtful behaviour, exposure to potentially harmful online content and issues related to excessive internet use. However, we did not include questions about children seeing sexual content and sending sexual messages to others ${ }^{3}$.

While this study has gathered valuable insights about the way New Zealand children interact with digital technologies, it is also important to acknowledge potential challenges and limitations. A common limitation of survey research is that it relies on self-reported data. Thus, there was a chance that children did not feel encouraged to provide accurate, honest answers and/or comfortable providing answers that presented themselves in an unfavourable manner. To manage this issue, we asked parents to allow their children to complete the survey alone. Due to the nature of the questions we also provided links to support services in case the children participating in the survey wished to seek advice or help.

\footnotetext{
2 Results from prior modules were included in our previously released report entitled Exploring New Zealand Children's Internet Access, Skills and Opportunities.

3 The reason for this was that Netsafe released two reports on teens and sexting and then experiences of digital harm. See https://www.netsafe.org.nz/advice/research/
} 
Another challenge was to retain children's engagement and attention with the online survey, particularly younger kids, as it could affect response rates. We made every effort to minimise the survey length. We managed to implement a 20-minute survey which was cognitively tested and piloted before it went live.

\section{What we found}

In this section we present the main findings regarding New Zealand children's experiences of online risks based on Global Kids Online's quantitative survey tool. Differences regarding age, gender, and ethnicity are included when rates are relevant.

\section{MEETING STRANGERS ONLINE}

To start with, participating children were asked whether they have ever had contact online with someone that they have not met previously face to face. As Figure 1 shows, responses to this broad question reveal that nearly 4 in $10 \mathrm{New}$ Zealand children (38\%) indicated they have had contact online with a stranger while $60 \%$ had not.

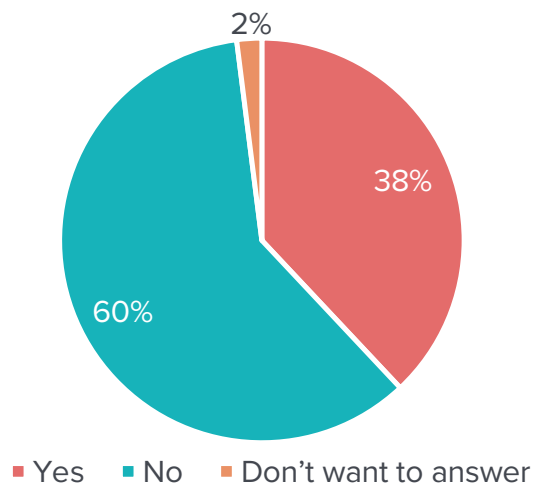

Figure 1. Children who had online contact with someone not met face to face

QK7. Have you ever had contact on the internet with someone you have not met face-to-face before?

Base: All children aged 9-17 ( $n=2,061)$

A closer look at the results in terms of age reveals that older children were more likely to have had contact via the internet with someone they have not met in person before. In this respect, $54 \%$ of children aged $15-17$ and $38 \%$ of those aged 12 to 14 years old said they done so. The rate was lower for younger kids aged 9-11 (23\%). See details in Figure 2.

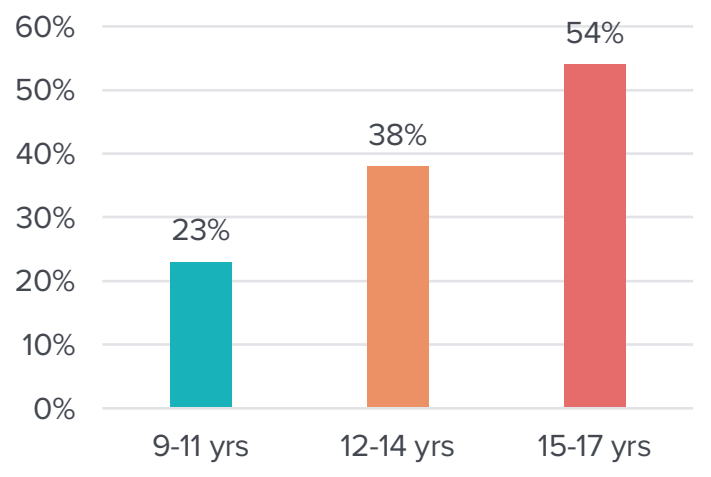

Figure 2. Children who had online contact with someone not met face to face by age

QK7. Have you ever had contact on the internet with someone you have not met face-to-face before?

Base: All children aged 9-17 ( $n=2,061)$

Meanwhile, regarding children's gender, more boys (42\%) reported to have had online contact with a stranger compared to girls (34\%). See Figure 3.

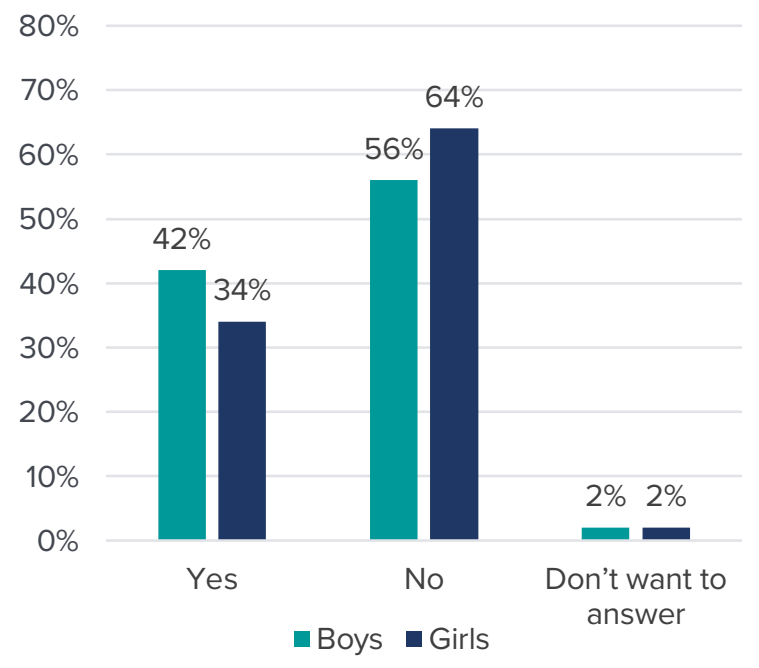

Figure 3. Children who had online contact with someone not met face to face by gender

QK7. Have you ever had contact on the internet with someone you have not met face-to-face before?

Base: All children aged 9-17 ( $n=2,061)$

We also asked children whether in the past year they had ever met anyone face to face that they first got to know online. Of all the children surveyed, a minority (10\%) indicated having gone on to physically meet an online contact. See Figure 4. 


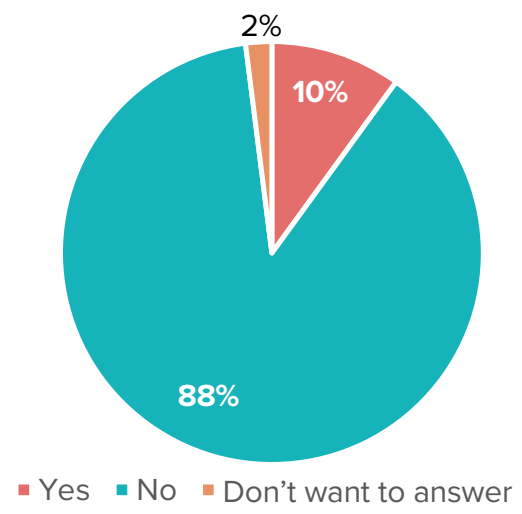

Figure 4. Children who in the past 12 months had gone to an offline meeting with someone previously met online

QK8A. In the past year, have you ever met anyone face-to-face that you first got to know on the internet?

Base: All children aged 9-17 $(n=2,061)$

While our data do not show significant differences in terms of gender $10 \%$ for both boys and girls) nor ethnicity, our findings regarding age do. As Figure 5 illustrates, younger children aged 9-11 (3\%) were less likely to have met face to face someone they first got to know online. The rate increased for 12-14year-olds (10\%) and was higher among those aged $15-17$ years $(18 \%)$.

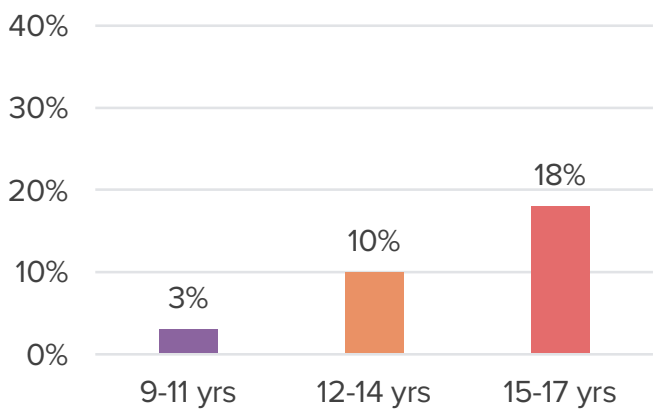

Figure 5. Children who in the past 12 months had gone to an offline meeting with someone previously met online by age

QK8A. In the past year, have you ever met anyone face-to-face that you first got to know on the internet?

Base: All children aged 9-17 ( $n=2,061)$

Children who had physically met up with an online contact were asked a follow-up question: When you met the person face-to-face that you first got to know on the internet, how did you feel about it? Of the 215 children who answered the question over 6 in 10 children (63\%) answered "I was happy". This was followed by those who said they were "not happy or upset" (25\%). The aggregated result from those children who felt "upset" was 7\% while 4\% preferred not to answer the question.

\section{BEING BOTHERED OR UPSET BY SOMETHING ONLINE}

The internet offers a number of opportunities and children in New Zealand are embracing them especially in regard to entertainment, learning and socialising (Pacheco \& Melhuish, 2019). However, the digital medium also brings some risks that can bother or upset them. In this sense, to explore risks and the potential harm they can cause, the survey included a general question asking children whether, in the last 12 months, there was anything online that bothered or upset them in some way. We explained that the online experience might include something that made them feel uncomfortable, scared or something that they should not have seen. As Figure 6 shows, a significant proportion of children (71\%) had not, but a quarter of them (25\%) reported to have had an online experience that bothered or upset them.

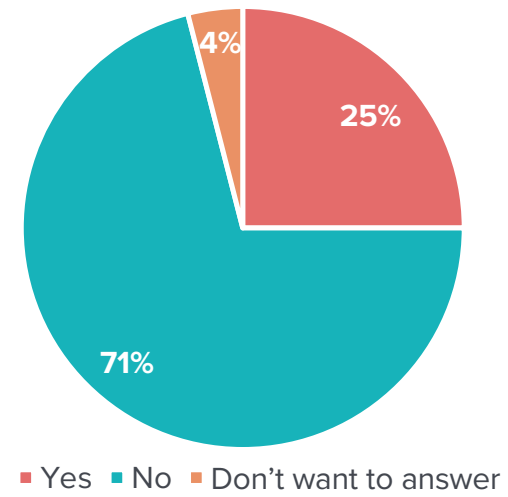

Figure 6. Children who were bothered or upset by something online

QK9A. In the past year, has anything ever happened online that bothered you or upset you in some way? (for example, made you feel uncomfortable, scared or that you shouldn't have seen it)

Base: All children aged 9-17 $(n=2,061)$

When looking at age groups, our findings show small fluctuations - see Figure 7. In this respect, the rate of children's bothersome or upsetting online experiences was $24 \%$ for 9-11-year-olds, while the results for children aged 12-14 and 1517 were $25 \%$ and $27 \%$, respectively. 


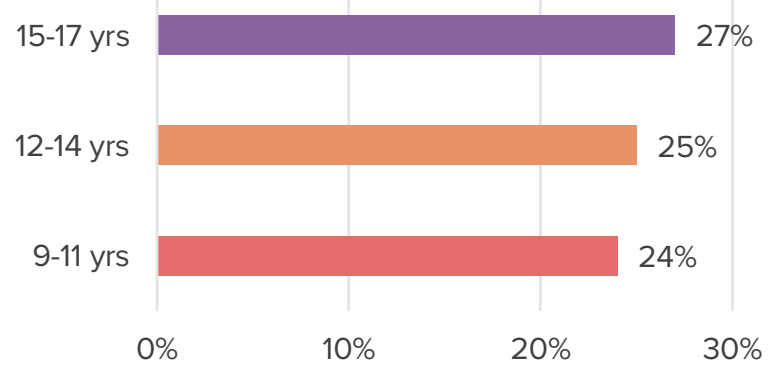

Figure 7. Children who were bothered or upset by something online by age

QK9A. In the past year, has anything ever happened online that bothered you or upset you in some way? (for example, made you feel uncomfortable, scared or that you shouldn't have seen it)

Base: Al/ children aged 9-17 ( $n=2,061)$

In terms of gender, girls (27\%) reported a slightly higher rate of bothersome online experiences compared to boys (23\%) in the last 12 months.

Meanwhile, for Māori (28\%) and NZ

European/Pākehā (27\%) it was slightly more common to be bothered by something they saw online compared to Pacific (23\%) and Asian (19\%) children.

A follow-up question asked children how often these experiences happened to them. According to the results, of those children who had been bothered by something online, a very large majority, 8 in 10, indicated that the upsetting online experience occurred "just once or twice" while $12 \%$ said it happened "at least every month". See Table 2 for further details.

Table 2. How often children were bothered or upset by something online in the past year

\begin{tabular}{|l|c|}
\hline $\begin{array}{l}\text { Frequency that children were bothered or } \\
\text { upset by something online }\end{array}$ & $\%$ \\
\hline Just once or twice & $81 \%$ \\
\hline At least every month & $12 \%$ \\
\hline At least every week & $4 \%$ \\
\hline Daily or almost daily & $2 \%$ \\
\hline Don't want to answer & $2 \%$ \\
\hline
\end{tabular}

QK9B. In the past year, how often did this happen?

Base: Children who have experienced something online that bothered or upset them in the last year $(n=515)$

To further explore this topic, we asked children who were bothered about something they experienced online $(n=515)$ how upset they were as a result of the incident. Aggregated results show that nearly half of them (46\%) indicated they had been "fairly upset" and "very upset" - see details in Table 3.

Table 3. How upset children were after an online experience bothered or upset them

\section{Children's emotional response to an upsetting online experience}

\begin{tabular}{|l|c|}
\hline I was a little upset & $44 \%$ \\
\hline I was fairly upset & $28 \%$ \\
\hline I was very upset & $18 \%$ \\
\hline I wasn't at all upset & $8 \%$ \\
\hline Don't want to answer & $1 \%$ \\
\hline
\end{tabular}

QK10. Thinking now about the last time this happened to you, how upset were you about what happened?

Base: Children who have experienced something online that bothered or upset them in the last year $(n=515)$

Children's emotional response is described in terms of age in Figure 8. The figure shows that more than a third of children aged 9-11 were fairly/very upset. However, the rate was higher among older kids. Half of children aged 12 and over indicated to have been fairly/very upset due to something they found online compared with younger kids.

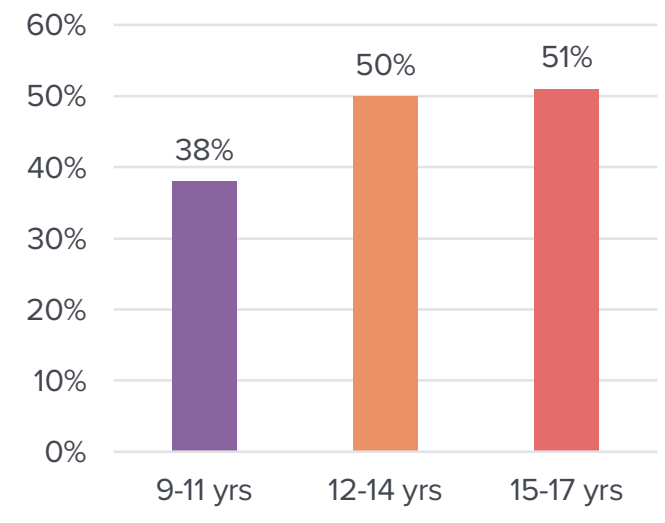

Figure 8. Children who were fairly/very upset after something online bothered or upset them by age

QK10. Thinking now about the last time this happened to you, how upset were you about what happened?

Base: Children who have experienced something online that bothered or upset them in the last year $(n=515)$

Being fairly/very upset was also more prevalent among girls. Among those children who had a bothersome online experience, around a half of girls (52\%) reported they had been fairly or very upset compared to boys (41\%) - see Figure 9. 


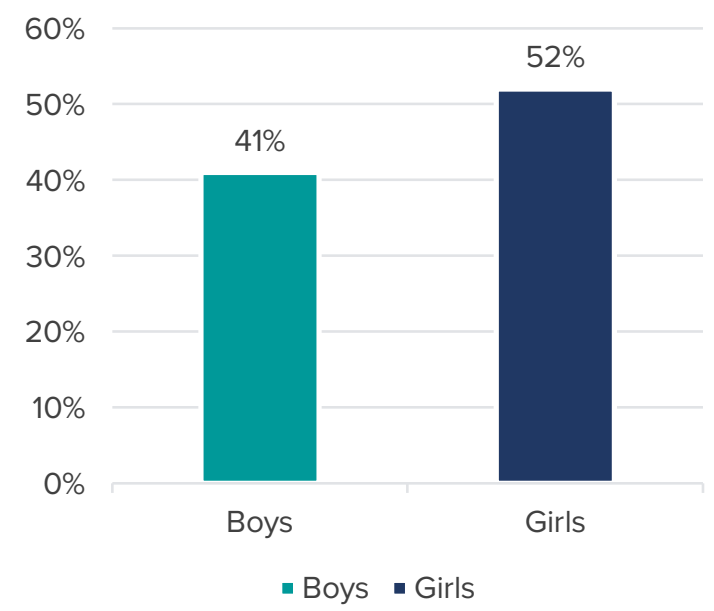

Figure 9. Children who were fairly/very upset after something online bothered or upset them by gender

QK10. Thinking now about the last time this happened to you, how upset were you about what happened?

Base: Children who have experienced something online that bothered or upset them in the last year $(n=515)$

In terms of ethnicity, Pacific children (58\%), followed by Māori (54\%) were more likely to be fairly or very upset. Rates were lower among NZ European/Pākehā (47\%) and Asian respondents (40\%).

Those children who said they were bothered by something online were also asked who they talked to about what had happened. Children could choose as many options as they wanted. Our results show that parents (69\%) were largely the first port of call followed by a friend (37\%) and then a sibling (17\%). A minority $(11 \%)$ of these respondents indicated they did not talk with anyone about the online experience - see details in Table 4.

Findings in the context of gender are presented in Table 5. As the table describes, boys and girls reported similar preferences in terms of the people they had chosen to talk with. However, interestingly, girls (41\%) were more likely to turn to a friend compared to boys (33\%).
Table 4. Who children talked with after an online experience that bothered or upset them

\begin{tabular}{|l|c|}
$\begin{array}{l}\text { Who children talked with after } \\
\text { experiencing something online that } \\
\text { bothered or upset them }\end{array}$ & $\%$ \\
\hline $\begin{array}{l}\text { My mother or father (or step/foster mother or } \\
\text { father) }\end{array}$ & $69 \%$ \\
\hline $\begin{array}{l}\text { A friend around my age } \\
\text { sibling) }\end{array}$ & $37 \%$ \\
\hline $\begin{array}{l}\text { I didn't talk to anyone } \\
\text { A teacher }\end{array}$ & $17 \%$ \\
\hline Another adult I trust & $11 \%$ \\
\hline Someone whose job it is to help children & $10 \%$ \\
\hline Someone else & $8 \%$ \\
\hline Don't want to answer & $3 \%$ \\
\hline
\end{tabular}

QK11. The last time something happened online that bothered you or upset you, did you talk to any of these people about it?

Base: Children who have experienced something online that bothered or upset them in the last year $(n=515)$

Table 5. Who children talked with after an online experience that bothered or upset them by gender

\begin{tabular}{|l|c|c|}
\hline $\begin{array}{l}\text { Who children talked with after } \\
\text { experiencing something online } \\
\text { that bothered or upset them }\end{array}$ & Boys & Girls \\
\hline $\begin{array}{l}\text { My mother or father (or step / foster } \\
\text { mother or father) }\end{array}$ & $71 \%$ & $68 \%$ \\
\hline $\begin{array}{l}\text { A friend around my age } \\
\text { My brother or sister (or step / foster / } \\
\text { half sibling) }\end{array}$ & $15 \%$ & $18 \%$ \\
\hline $\begin{array}{l}\text { I didn't talk to anyone } \\
\text { A teacher }\end{array}$ & $11 \%$ & $10 \%$ \\
\hline $\begin{array}{l}\text { Another adult I trust } \\
\text { Someone whose job it is to help } \\
\text { children }\end{array}$ & $10 \%$ & $10 \%$ \\
\hline $\begin{array}{l}\text { Someone else } \\
\text { Don't want to answer }\end{array}$ & $2 \%$ & $10 \%$ \\
\hline
\end{tabular}

QK11. The last time something happened online that bothered you or upset you, did you talk to any of these people about it?

Base: Children who have experienced something online that bothered or upset them in the last year $(n=515)$ 
As talking with parents and a friend were the preferred actions of children who were bothered by an online experience, we looked closely at the data describing these two aspects in the context of age. Talking with parents was most prevalent among younger children aged 911 years old (79\%) with percentages steadily declining among older age groups.

Nevertheless, approaching their parents remained the most prevalent action overall for all age groups. In contrast, the opposite trend was found regarding children talking with a friend for support with $28 \%$ of younger children (9-11) and $46 \%$ of $15-17-y e a r-o l d s$ taking this action - see details in Figure 10.

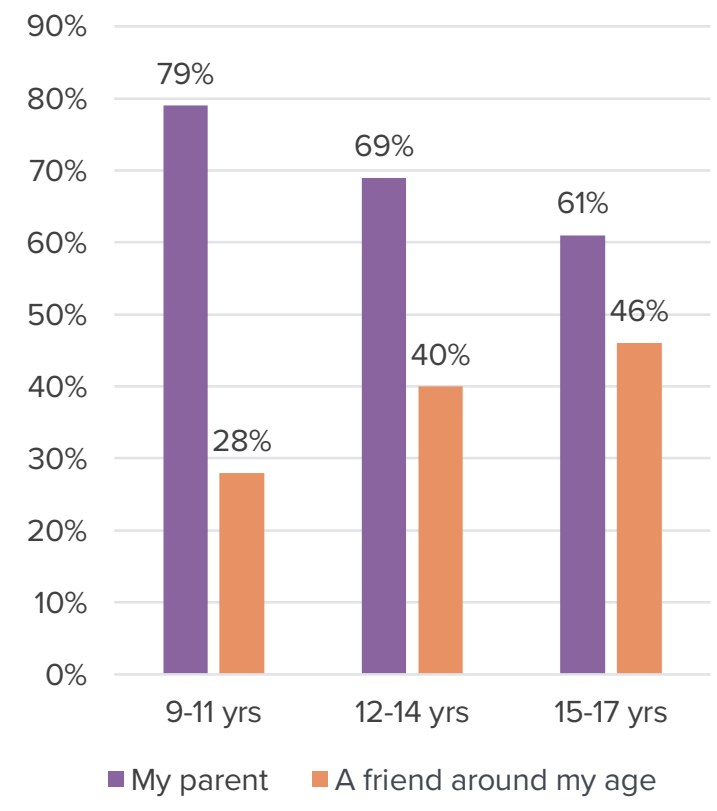

Figure 10. Who children talked with after something online bothered or upset them by age - parents and a friend

QK11. The last time something happened online that bothered you or upset you, did you talk to any of these people about it?

Base: Children who have experienced something online that bothered or upset them in the last year $(n=515)$

Regarding ethnicity, it was more common for Māori (75\%) and NZ European/Pākehā (71\%) to talk with their parents after experiencing an online incident, with $69 \%$ of Pacific children taking a similar approach while the rate was lower among Asian children (53\%).

\section{EXPERIENCES OF AND ENGAGEMENT IN HURTFUL BEHAVIOUR}

In this section, we describe results regarding children's experiences of and engagement in hurtful behaviour not only in person but also online. We started by asking a broad question about whether anyone had treated them in a hurtful or nasty way in the prior year. As Figure 11 depicts, nearly a quarter of children answered affirmatively to the question.

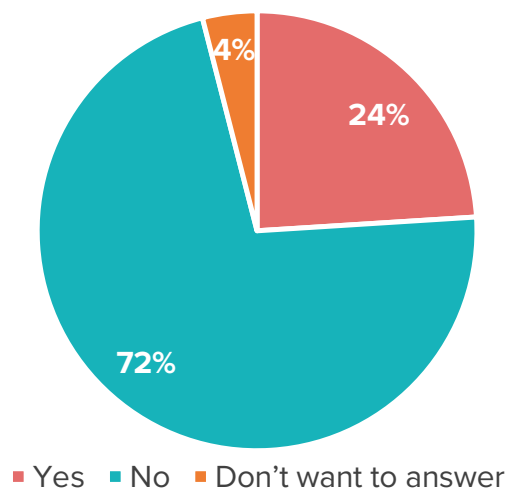

Figure 11. Children who have been treated in a hurtful or nasty way in the past 12 months

QK12. In the past year, has anyone ever treated you in a hurtful or nasty way?

Base: All children aged 9-17 ( $n=2,061)$

Results on the basis of children's gender show a slightly higher prevalence for girls (26\%) compared to boys (23\%).

In terms of age, this sort of experience was more common for those aged 12-14 years old (26\%). Rates for younger and older children were lower as $22 \%$ of children aged 9-11 and

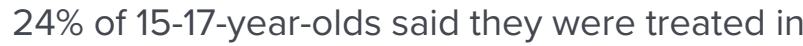
a hurtful way in the last 12 months - see Figure 12.

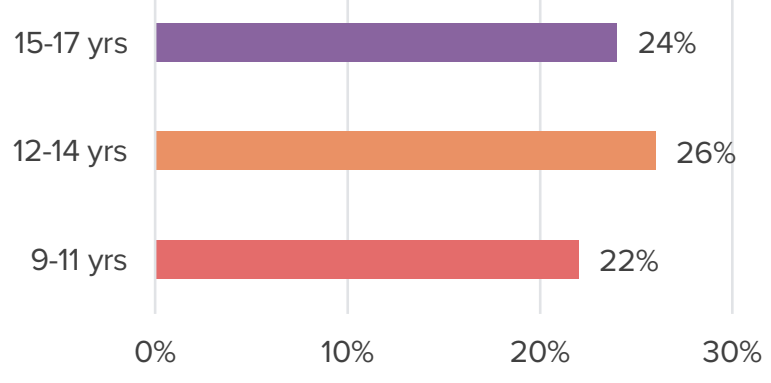

Figure 12. Children who have been treated in a hurtful or nasty way in the past 12 months

QK12. In the past year, has anyone ever treated you in a hurtful or nasty way?

Base: All children aged 9-17 $(n=2,061)$

Those children who indicated having been treated in a nasty way were asked whether that experience occurred in person or online. Put in the context of the whole research sample, $16 \%$ of all children said they were treated in a nasty 
way face to face in the prior year, while $15 \%$ had a similar experience online. Also, $9 \%$ of these children said they were treated in a hurtful way both in person and online.

Looking at the results in terms of gender, girls were more likely to be treated badly, both online and in person, compared to boys - see Figure 13 for details.

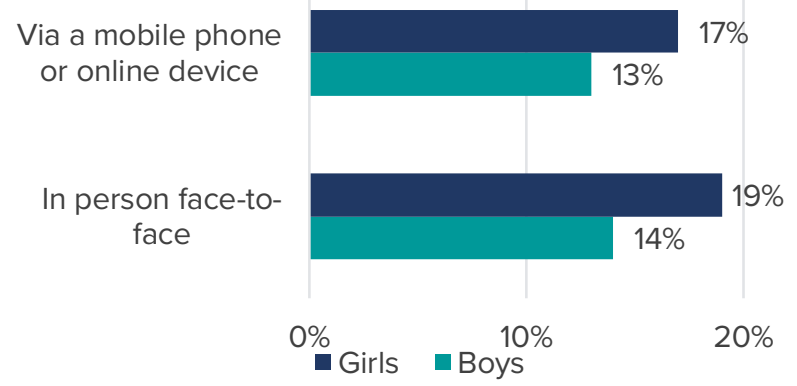

Figure 13. Children who have been treated in a hurtful or nasty way in the past 12 months by gender - In person or online

QK13. When someone has treated you in this way, how has it happened?

Base: Al/ children aged 9-17 ( $n=2,061)$

In terms of age, the most noticeable difference can be found among younger children. As Figure 14 illustrates 9-11-year-olds were nearly twice as likely to be treated badly in person than online.

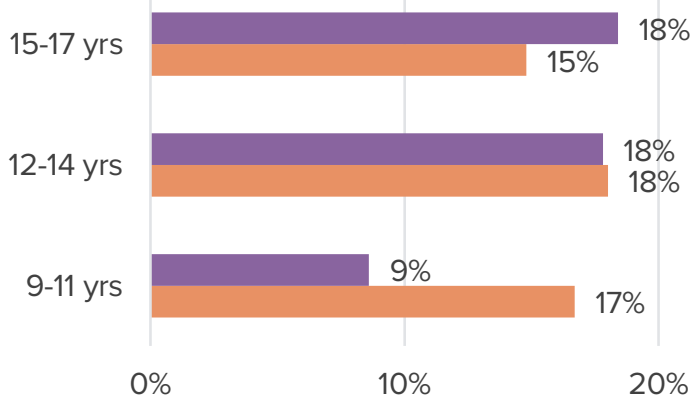

- Via a mobile phone or online device - In person face-to-face

Figure 14. Children who have been treated in a hurtful or nasty way in the past 12 months by age - In person or online

QK13. When someone has treated you in this way, how has it happened?

Base: A/l children aged 9-17 $(n=2,061)$

Participants who reported being treated in a hurtful or nasty way online in the past 12 months $(n=295)$ were also asked about how they felt regarding the incident. Overall, $60 \%$ of these children indicated to have been fairly/very upset about the negative experience - see Table 6 . However, for girls (65\%), it was more common to have felt fairly or very upset than in boys (47\%). Compared to NZ European/Pākehā and Māori, both $63 \%$, Pacific children (76\%) were more likely to feel fairly/very upset.

Table 6. How upset children were after being treated in a hurtful or nasty way online by others

\begin{tabular}{|l|c|}
\hline $\begin{array}{l}\text { Children's emotional response to a } \\
\text { hurtful situation }\end{array}$ & $\%$ \\
\hline I was a little upset & $34 \%$ \\
\hline I was fairly upset & $31 \%$ \\
\hline I was very upset & $29 \%$ \\
\hline I wasn't at all upset & $5 \%$ \\
\hline Don't want to answer & $1 \%$ \\
\hline
\end{tabular}

QK14. Thinking of the last time someone treated you in a hurtful or nasty way online, how did you feel?

Base: Children aged 9-17 who answered QK14 (n=301)

The survey also included a question which focused on other online risks mainly related to privacy and security. The question included five statements and children chose between "yes", "no" and "don't want to answer" - see Figure 15 for details.

The results show that, in the past year, just over 1 in 10 children (12\%) have had a virus or spyware on their digital device. This sort of incident was more common for boys (14\%) than for girls $(10 \%)$ and higher among teens aged 15$17(15 \%)$ compared to their 9-11- and 12-14-yearold peers, $11 \%$ for each of these age groups. This sort of online risk was also more common for Pacific (15\%) and Māori (14\%) children.

Meanwhile, about $10 \%$ of children indicated that someone had used their password to access their personal information or to pretend to be them. While no statistical differences were found in terms of gender, the incidence in regard to ethnicity was slightly higher for Pacific (14\%) and Māori (13\%) children than for other children. Also, the prevalence of this sort of online incident tended to steadily increase by children's age. In this respect, $8 \%$ of $9-11$ and $11 \%$ of 12-14 years old children reported that someone used their password to access their personal information or to pretend to be them while the rate was $13 \%$ for teenagers aged 15-17. 


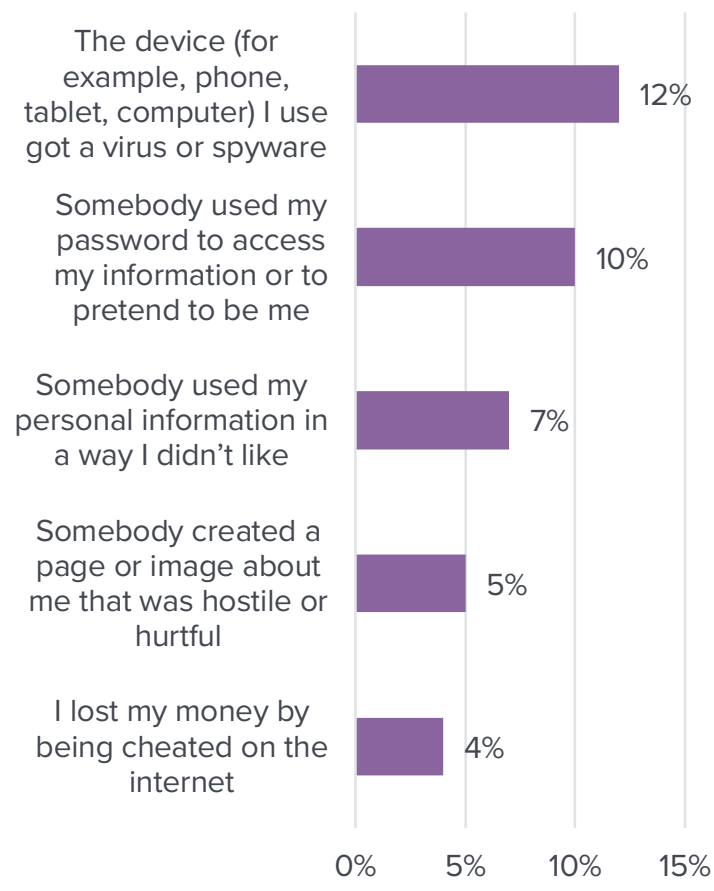

Figure 15. Children's experiences of other online risks

QK21. In the past year, has any of the following happened to you on the internet?

Base: All children aged 9-17 ( $n=2,061)$

Other results include: $7 \%$ of children said somebody used their personal information in a way they did not like and 5\% reported that somebody created a page or image about them that was hostile or hurtful. Finally, the percentage of kids who said they lost money after being cheated online was $4 \%$.

There were not any significant statistical differences regarding gender, however it was slightly more common for boys (14\%) to have had their device infected with a virus or spyware compared to girls (10\%).

We were also interested in collecting data about children' personal engagement with hurtful behaviour against their peer(s). In this respect, we asked all participating children whether they had treated someone else badly in the past year. Figure 16 shows that just under 1 in 10 children (9\%) did so in the past year. As children were much less likely to report treating others badly, compared to having been treated badly by others (see Figure 11), it might be that kids were under-reporting or lacked awareness that their behaviour was hurtful to others.

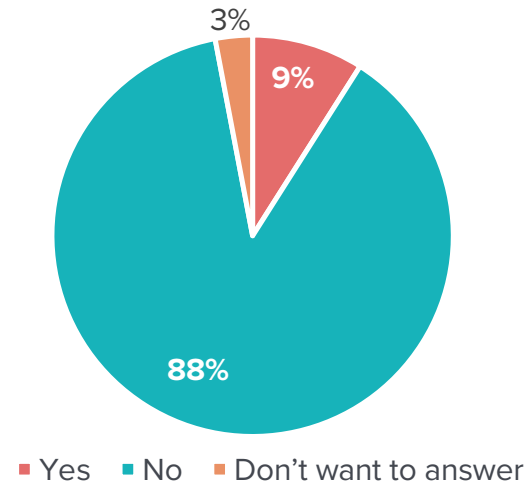

Figure 16. Children who treated others in a hurtful way

QK15. In the past year, have you ever treated someone else in a hurtful or nasty way?

Base: All children aged 9-17 (n=2,061)

Both, girls and boys reported the same rates of engagement in hurtful behaviour against others (each 9\%). However, it was slightly more common for Māori to report they have treated others badly in the past year (13\%) compared to NZ European/Pākehā and Pacific children (10\% for each). The lowest rate of engagement in hurtful behaviour was reported by Asian children (5\%).

When looking at age groups, our findings show some differences particularly between 12-14 years old (13\%) and those aged 9-11 years old (7\%) and $15-17$ years old teens (8\%). See Figure 17.

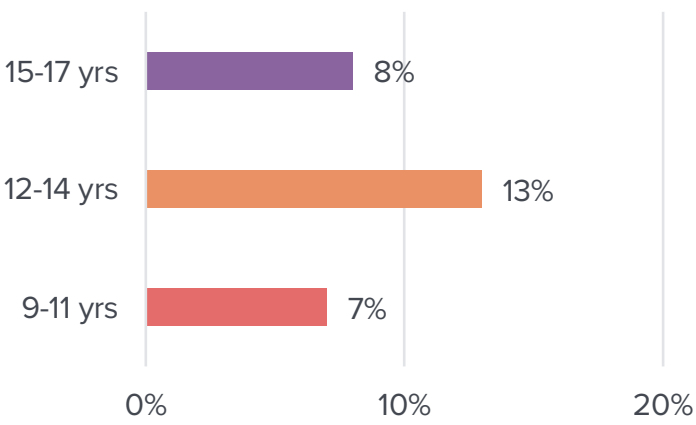

Figure 17. Children who treated other in a hurtful way by age

QK15. In the past year, have you ever treated someone else in a hurtful or nasty way?

Base: All children aged 9-17 ( $n=2,061)$

Those children who indicated they had treated someone else badly $(n=189)$ were asked whether it happened in person or online. Our data show similar rates, about $6 \%$ for both behaviours. Only $3 \%$ of children reported to have treated a peer in a nasty way both in person and online. 
EXPOSURE TO POTENTIALLY HARMFUL ONLINE CONTENT

In this section we present results about children's exposure to potentially harmful online content in the prior year. We were interested in exploring whether children have encountered any content (e.g. images, video, audio or text) posted online by other users, namely usergenerated content. In the survey potentially harmful online content referred to: ways of physically harming or hurting themselves, ways of committing suicide, ways to be very thin (such as being anorexic or bulimic), hate messages that attack certain groups of individuals (for example, people of different colour, religion or nationality), their experiences of taking drugs and gory or violent images. Due to the sensitive nature of the topics addressed, only teenagers aged between 13 and 17 years old were asked the question.

Overall, $47 \%$ of New Zealand teenagers, nearly half, have been exposed to one or more types of potentially harmful online content in the prior year. Rates in terms of age were higher among $17-y e a r-o l d s(58 \%)$. Percentages for teens aged 14, 15 and 16 were fairly similar: 49\%, 50\% and $47 \%$, respectively. Meanwhile the rate for 13 year-olds was the lowest (33\%).

Results regarding exposure to every type of potentially harmful online content are presented in Figure 18. According to our results, over a third of teens aged 13-17 years old (36\%) have seen gory or violent images on websites and online discussions while $27 \%$ have been exposed to hateful online content. Also 1 in 4 teens $(26 \%)$ said they had seen websites or online discussions where people talk about their experiences of taking drugs. Meanwhile, 1 in 5. (20\%) indicated having been exposed to content related to self-harming behaviours. Less common were exposure to online content related to ways of committing suicide (17\%) and seeing content related to ways of being very thin (15\%).

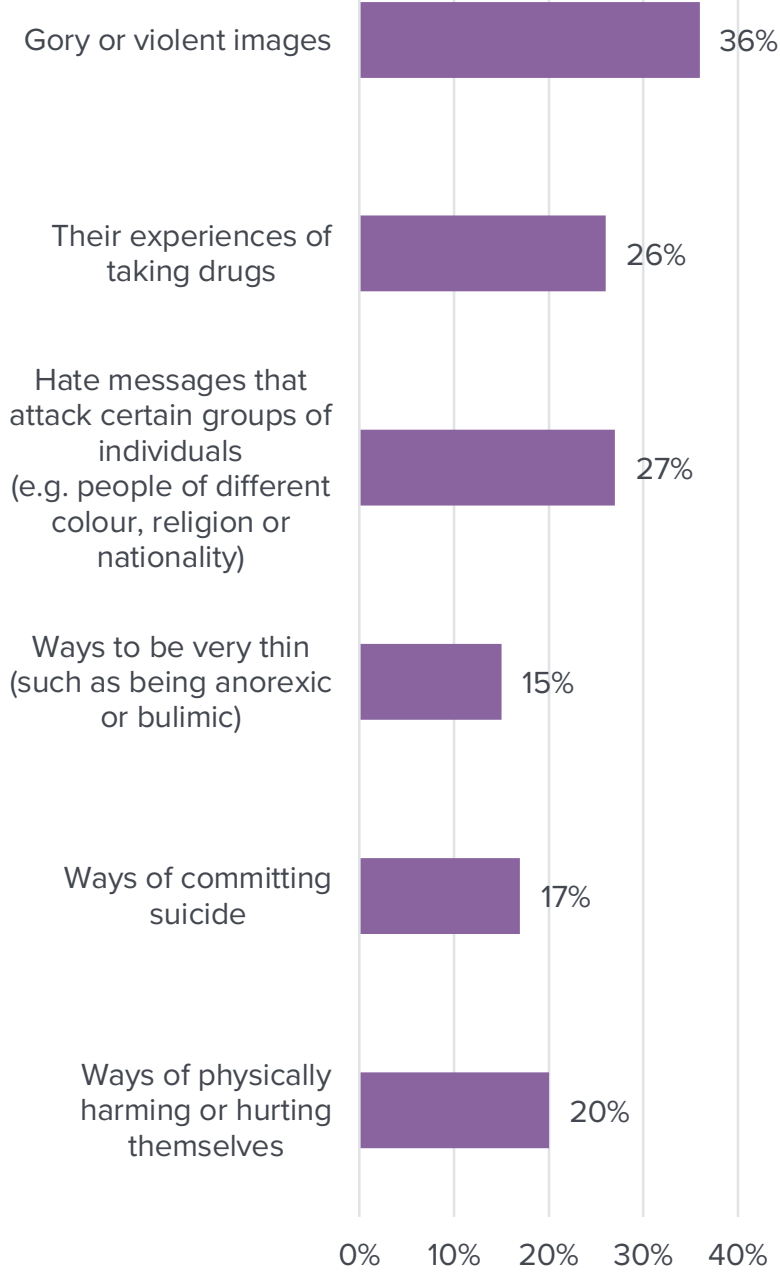

Figure 18. Teens who have seen potentially harmful online content in the past 12 months

QK40. In the past year, have you seen websites or online discussions where people talk about or show these things?

Base: All children aged 13-17 (n=1032)

In terms of gender, overall girls were more likely to be exposed to a range of potential harmful online content than boys. For example, it was more common for girls (29\%) to encounter hateful messages attacking certain groups (e.g. people of a different colour, religion or nationality) than boys (24\%). A similar trend of higher exposure to potentially harmful online content among girls compared to boys was found in relation to experiences of content related to ways of committing suicide, experiences of taking drugs, ways of physically self-harming, and ways to be very thin. However, for boys (38\%) it was more common to encounter gory or violent images on the internet than for girls (33\%). See details in Figure 19. 


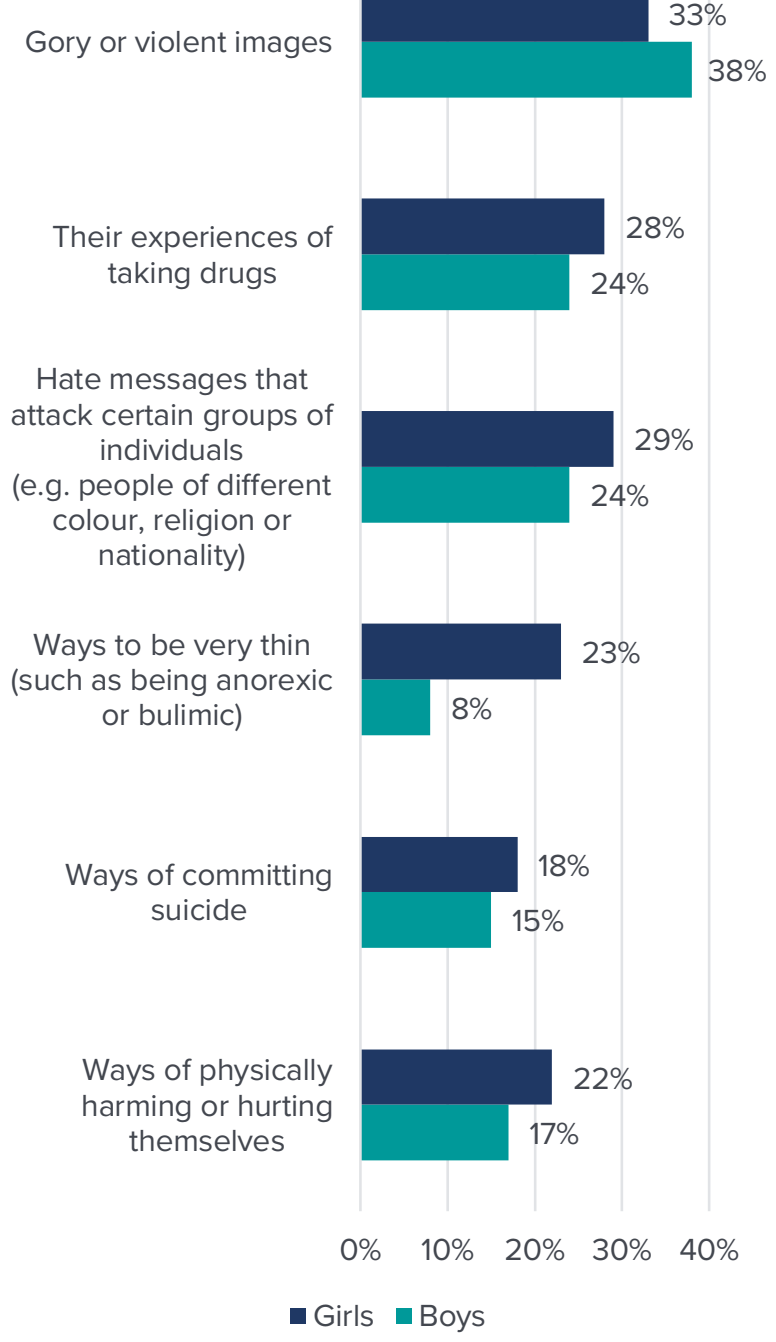

Figure 19. Teens who have seen potentially harmful online content in the past 12 months by gender

QK40. In the past year, have you seen websites or online discussions where people talk about or show these things?

\section{Base: All children aged 13-17 (n=1032)}

Meanwhile, Figure 20 depicts findings in the context of children's age. Our data show that exposure to some forms of potentially harmful online content increased with children's age. For example, exposure to violent images was reported by $27 \%$ of kids aged 13 years old. The rate increased to $44 \%$ for 17 -year-old teens while differences for kids aged between 14 and 16 were nuanced. Regarding exposure to hateful speech and experiences of taking drugs, the prevalence was higher among 17-year-olds, $35 \%$ and $38 \%$.

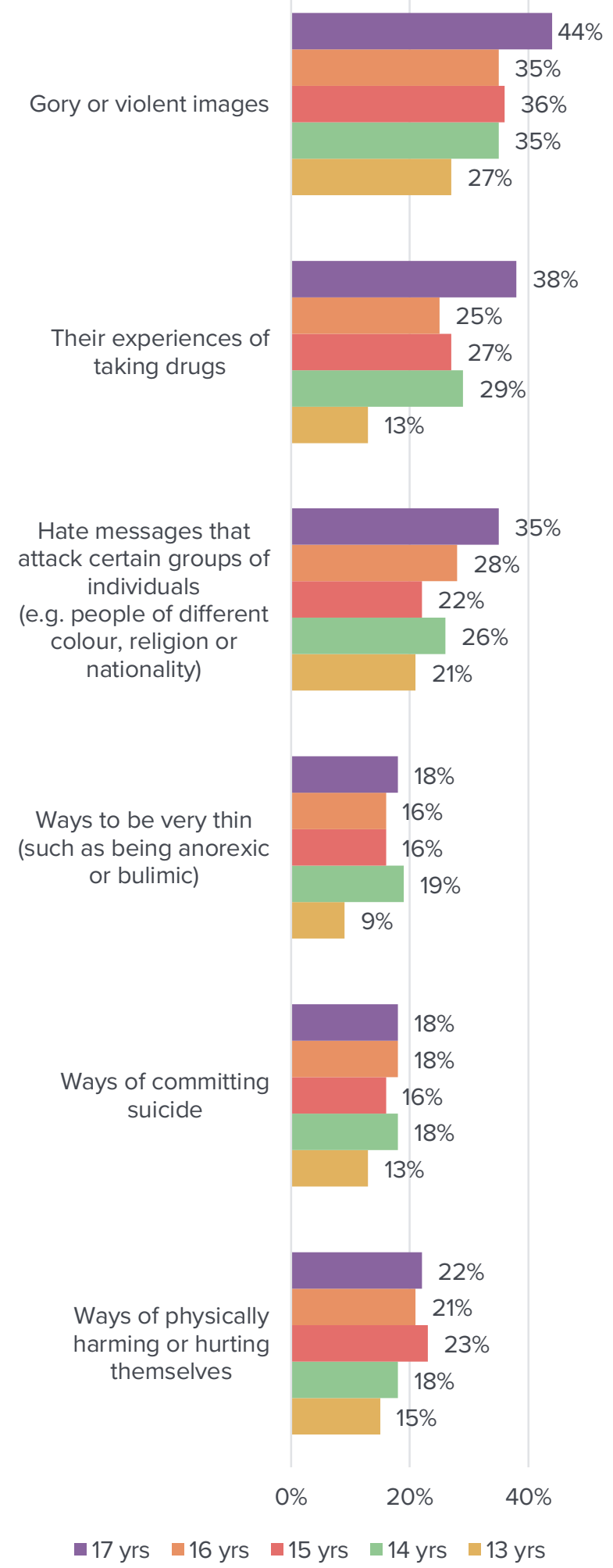

Figure 20. Teens who have seen potentially harmful online content in the past 12 months by age

QK40. In the past year, have you seen websites or online discussions where people talk about or show these things?

Base: All children aged 13-17 (n=1032) 
Those teenagers who said they were exposed to potentially harmful online content were asked a follow-up question about how upset the experience made them feel. A total of 502 teens answered it. Aggregated results show that nearly 3 in 10 teens (28\%) were fairly/very upset. See details in Table 7.

Table 7. Children's emotional response to potentially harmful online content

\begin{tabular}{|l|c|}
\hline $\begin{array}{l}\text { Teens' emotional response to } \\
\text { potentially harmful online content }\end{array}$ & $\%$ \\
\hline I wasn't at all upset & $24 \%$ \\
\hline I was a little upset & $41 \%$ \\
\hline I was fairly upset & $20 \%$ \\
\hline I was very upset & $8 \%$ \\
\hline Don't want to answer & $6 \%$ \\
\hline
\end{tabular}

QK41. Please think about the last time you saw this kind of content online. Which of these best describes how you felt about it?

Base: Children aged 13-17 who have seen harmful content ( $n=502)$

Interestingly, when looking at the results in terms of gender, teenage girls (38\%) reported a much higher emotional impact of exposure to this sort of online content (being fairly/very upset) compared to boys (18\%).

\section{EXCESSIVE INTERNET USE}

Finally, all participating teens aged 13-17 were asked how frequently they experienced some issues related to excessive internet use. The question included five statements and the children were asked to choose from a six-point scale for each statement: "Very often", "Often", "Sometimes", "Hardly ever", "Never", and "Not sure/Don't want to answer".

Overall, relatively few teenagers reported frequent (often/very often) negative impact of excessive internet use - see Figure 21.
I have gone without eating or sleeping because of the time I spent on the internet

I have
experienced
conflicts with
family or friends
because of the
time I spent on
the internet
My results at
school have
dropped
because of the
time I spent on
the internet

I have tried
unsuccessfully
to spend less
time on the
internet
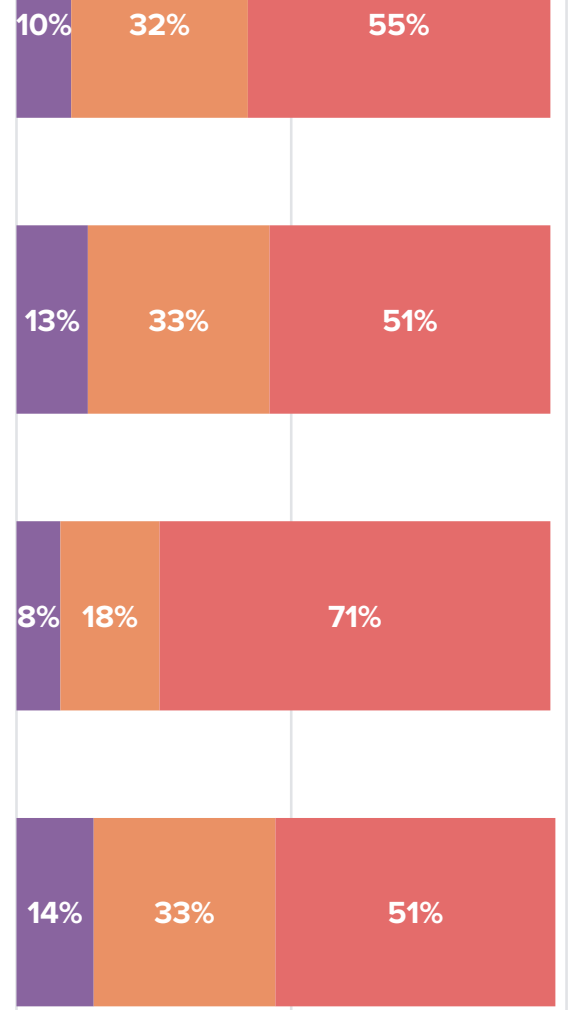

I think the amount of time I spend on the internet causes problems for me

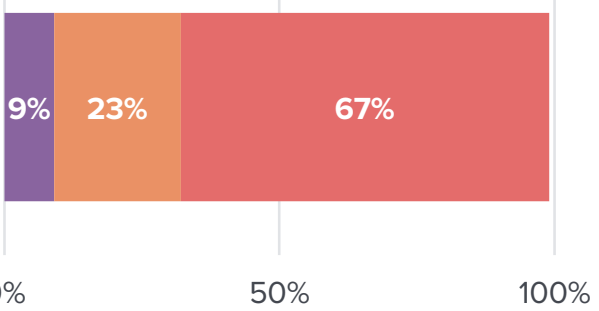

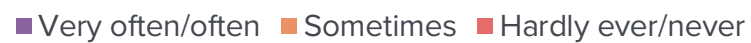

Figure 21. Teens who reported the impact of excessive internet use in the last 12 months

QK42. In the past year, how often have these things happened to you?

Base: All children aged 13-17 (n=1032)

For example, $14 \%$ said they have experienced conflicts with family or friends because of the time they spent on the internet while $13 \%$ indicated having unsuccessfully tried to spend less time online. Also 1 in 10 teens (10\%) considered that the amount of time they spend on the internet is causing problems for them. Low rates were also reported by teens in regard to having gone without eating or sleeping (9\%) and getting lower marks at school due to excessive internet use (8\%). Overall, $27 \%$ of 
children reported often or very often

experiencing at least one of the different impacts of excessive internet use we asked them about in the last 12 months.

The only significant difference between teenage boys and girls in aspects related to excessive internet use was in their unsuccessful attempts to spend less time online. In this respect, there was a moderate difference for girls (15\%) compared to boys (11\%).

In regard to ethnicity, our results show that Pacific teens were more likely to say their school results have deteriorated because of the time they spend online (19\%) compared to Māori (11\%) and NZ European/Pākehā adolescents (7\%). A similar trend was found regarding teens' unsuccessful attempts to spend less time on the internet. Pacific children reported the highest rate (21\%). This was followed by Māori (16\%) and NZ European/Pākehā teenagers (13\%), for instance. On the other hand, Māori teens were more likely to say that they experienced conflicts with family or friends because of the time they spend online (17\%). Rates for NZ European/Pākehā and Pacific adolescents were $14 \%$ and $13 \%$, respectively. Overall, younger teenagers (13-15-year-olds) more commonly experienced conflict with family or friends due to the time they spend online. This was particularly higher for 15 -year-olds (20\%).

\section{Concluding remarks}

The purpose of this report was to present research-based evidence regarding the incidence of online risks and perceived harm among New Zealand children ${ }^{4}$. The findings described here are part of $\mathrm{Ngā}$ taiohi matihiko o Aotearoa - New Zealand Kids Online, a research project that seeks to explore the experiences of children aged 9-17 and their parents in regard to technology access, use, skills and opportunities as well as risks and harm.

\section{ONLINE EXPERIENCES THAT BOTHER OR UPSET CHILDREN}

As reported, a quarter of New Zealand children have experienced things online that bothered or upset them. Rates are similar in terms of children's age. However, for girls as well as Māori and NZ European/Pākehā children, it is more common to have seen content online that bothered them. What is more, nearly half of those children reported that they felt fairly or very upset. Girls, children aged 12 years old and over, as well as Māori and Pacific children are likely to feel more upset due to the experience. The findings suggest that while some children seem to be more able to manage the emotional toll of bothersome online experiences, others are finding it hard to cope with them ${ }^{5}$. These findings will be of interest to policy makers, educators and parents as they not only describe children's perceived harm in the context of gender, age, and ethnicity but also suggest the need to provide additional support for those who are more likely to be emotionally affected. Therefore, in parallel to other preventive measures, it might be necessary to help children through additional approaches such as the development of resilience ${ }^{6}$. In doing so, they will be prepared to better deal with potential distress caused by some online experiences.

\footnotetext{
4 However, it is necessary to make a distinction between risk and harm. While certain online activities such as sharing nudes or watching sexual content represent a risk, they might not cause harm to children nor affect them equally (Livingstone, 2013).

5 These findings are consistent with the results from a 2017 Netsafe study conducted with teenagers, especially in regard to gender and ethnicity (Pacheco \& Melhuish, 2018d).

6 Resilience is defined as "relative resistance to environmental risk experiences or the overcoming of stress or adversity" (Rutter, $2006, \mathrm{p} .2$ ).
} 


\section{SEEKING SUPPORT FOR UPSETTING EXPERIENCES}

Similarly, the study reveals that the role of parents and close friends is critical to children when they are dealing with upsetting online experiences. Further, our findings show that parents are largely the first line of support for their children, reflecting our 2017 study on teenagers' online experiences (see Pacheco \& Melhuish, 2018c). What is more, the findings provide deeper insights as they show that the importance of parents' and peers' supporting role changes as children get older. For example, younger kids aged 9-11 were approximately three times more likely to talk with their parent than a friend. As kids become older, parents' role as a source of support is not only less prevalent but is also balanced by a substantial increase in the importance of close friends (see Figure 10). Similarly, for girls, reaching out to a close friend to talk about a bothersome online experience is more significant than for boys. All this suggests that, along with mediating, in different forms, their children's internet use to prevent potential harm, parents also need to be prepared and informed to provide the best support possible to their children, particularly the younger ones, once the distressing experience has occurred. While we did not ask participants about the outcomes of their conversations with their parents or peers, there is evidence of the positive impact that the support from social connections has in children managing unwanted online content and/or abusive behaviours (Connor \& Buccahan, 2017; Cowie, 2011; Pacheco \& Melhuish, 2018c). Similarly, the growing role of close friends' support as children get older presents an opportunity to explore peer-to-peer support approaches in the context of online safety. In this respect, Netsafe has recently implemented Youth Action Squad (YAS), an initiative seeking to enhance peer-to-peer support. YAS involves a group of young people talking with other children about online safety, giving advice and exploring ideas about how to make the online space safer in New Zealand 7 . Implementing youth-led programmes is one of many ways to support children's safety but it can complement existing approaches and have a role in preventing and helping kids to manage online risks and potential harm.

\section{ENGAGEMENT IN HURTFUL BEHAVIOUR}

In addition to being exposed to bothersome online content, 1 in 4 New Zealand children aged 9-17 said that someone has treated them badly in the past year, either in person or online. Interestingly, kids are equally likely to be treated in a nasty way in person and online. This finding contrasts with those from most Global Kids Online members who report a higher incidence of in-person hurtful treatment ${ }^{8}$.

In addition, 6 in 10 kids who were treated badly online say they felt fairly or very upset. On the other hand, a minority of New Zealand kids have engaged in hurtful behaviour against someone else. However, this type of behaviour is higher among 12-14 year olds ${ }^{9}$ coinciding with their transition into secondary school. This suggests that greater efforts are needed to provide them with adequate support (education programmes, campaigns and resources) to encourage positive and respectful behaviours and help them to realise the implications of abusive behaviour on others.

\section{EXPOSURE TO POTENTIALLY HARMFUL ONLINE CONTENT}

The findings in this study also shed new light on 13-17-year-old teens' exposure to different forms of potentially harmful online content. In general, a significant proportion of teens had not encountered this sort of material. However, among those who did, rates vary depending on the type of user-generated content they were exposed to. For example, seeing violent images (36\%) was the most common experience for teens followed by exposure to hateful speech and content about drug taking (over a quarter for both). It is noteworthy to mention that

\footnotetext{
7 For information about YAS see https://www.netsafe.org.nz/yas/

${ }^{8}$ For example, Italy, Bulgaria, Albania, Czech Republic and Chile. For details see http://globalkidsonline.net/

9 This insight regarding age reflects findings regarding victimisation and bullying in New Zealand. See Kljakovic, Hunt, and Jose (2015).
} 
exposure to these three forms of potentially harmful online content increase as teens become older. Another interesting finding is that girls' exposure to five of the six types of online harmful content surveyed was higher compared to boys (see Figure 19). For example, and interestingly, exposure to content about ways to be very thin (e.g. anorexic or bulimic) was much higher in girls compared to boys, while it was more common for boys to see violent images online. Although we did not ask teenagers whether exposure to this sort of content was accidental or intentional, our findings provide interesting insights about the emotional impact of this sort of content, with less than a third of teens saying they were fairly or very upset.

\section{CHILDREN'S PERCEPTIONS OF EXCESSIVE INTERNET USAGE}

Similarly, this research contributes to the understanding of children's excessive internet use in New Zealand. The findings show that relatively few children report some adverse effects such as managing the time spent on the internet or the negative impact of excessive internet use on their school grades as well as their relationships with parents and friends. Since the early days of the internet, there has been a debate on the topic based on contrasting evidence. On one side, some studies suggest that excessive internet use is associated, for instance, with obesity (Kautiainen, Koivusilta, Lintonen, Virtanen, \& Rimpelä, 2005), a limited ability to communicate socially in an effective way (He, Liu, Guo, \& Zhao, 2011), and is linked to antisocial behaviour, decreasing happiness but also increasing loneliness, depression and political disengagement (Twenge, 2017). As a result, governments around the world have responded with policies and strategies to reduce excessive technology usage. For instance, in $2017 \mathrm{New}$ Zealand's Ministry of Health released its national screen time guidelines for children under 5 years old ${ }^{10}$. On the other side, recently, longitudinal research has presented inconclusive results or found small associations between teens' wellbeing and the time they spend on social media and video games (see Etchells, Gage, Rutherford, \& Munafò, 2016; Orben, Dienlin, \& Przybylski, 2019; Parkes, Sweeting, Wight, \& Henderson, 2013; Smith, Ferguson, \& Beaver, 2018). As the lack of consensus is evident, excessive internet use will remain an area for further research. A natural progression of future work is to analyse, for instance, the role of different levels of parental mediation in the rates reported by New Zealand teens, the link between excessive internet use and vulnerable children, the adequacy and/or methodological challenges of measuring time spent online to understand teens' wellbeing, and the role of other risk factors. Meanwhile, as the findings of this report show that some children themselves believe their use is excessive, there is an opportunity for parents to engage those children in fruitful conversations about how this can be managed.

\section{MEETING STRANGERS ONLINE}

Finally, before this study, New Zealand-based evidence of the incidence of so-called "stranger danger" was purely anecdotal. Since the early days of the internet, news media stories have portrayed and influenced public discourse on the dangers of children meeting strangers (Mascheroni, Jorge, \& Farrugia, 2014). In this respect, one of the main online concerns of New Zealand parents is their children meeting in person someone they first got to know on the internet (Pacheco \& Melhuish, 2018a). Our findings show that, in contrast to what most adults might be afraid of, a minority of kids, 1 in 10 , has met a stranger in person. The concern is that meeting a stranger represents a risk and might end up resulting in harm to children. However, interestingly, the majority of these children indicated that the experience was positive for them. This suggests that children who are contacted by strangers seem to be making discerning choices about who and how they interact with online and in person. These choices might also be explained by the trust that children report having in their parents when online issues arise and parents' reported approaches to online risk. Our previous studies

${ }^{10}$ See https://www.health.govt.nz/publication/sit-less-move-more-sleep-well-active-play-guidelines-under-fives 
show that children seek and rely on the support and advice of their parents and that parents tend to remain calm and talk with their kids when an online incident occurs (Pacheco \& Melhuish, 2018a, 2018c). Another explanation could be schools' strategies and policies regarding online safety which might create awareness among most children in regard to this and other online risks.

\section{What's next?}

Netsafe will be publishing more findings from Ngā taiohi matihiko o Aotearoa - New Zealand Kids Online about parental mediation of children's digital experiences. To learn more about this and our other research work contact: research@netsafe.org.nz

Netsafe provides a collection of online safety resources free and available to all New

Zealanders at:

https://www.netsafe.org.nz/the-kit/resourcecentre/

Netsafe also provides resources specifically developed for educators at:

https://www.netsafe.org.nz/the-kit/

\section{About Global Kids Online}

Global Kids Online is an international network of academics, social researchers, and experts dedicated to the study of children's rights, risks and opportunities in the digital age. Its purpose is to generate rigorous cross-national researchbased evidence regarding the way children access and use the internet and to understand the risks and opportunities of their interaction with digital tools.

Global Kids Online is an initiative of UNICEF's Office of Research-Innocenti, the London School of Economics and Political Science (LSE), and EU Kids Online. Find out more at: https://globalkidsonline.net/

\section{References}

Connor, H., \& Buccahan, L. (2017). Leadership through peer mediation: Research report. Retrieved October 22, 2019, from

https://unitec.researchbank.ac.nz/handle/10652/3833

Cowie, H. (2011). Peer support as an intervention to counteract school bullying: Listen to the children. Children \& Society, 25(4), 287-292. https://doi.org/10.1111/j.1099-0860.2011.00375.x

Etchells, P. J., Gage, S. H., Rutherford, A. D., \& Munafò, M. R. (2016). Prospective investigation of video game use in children and subsequent conduct disorder and depression using data from the Avon Longitudinal Study of Parents and Children. PloS One, 111), e0147732. https://doi.org/10.1371/journal.pone.0147732

Fenaughty, J., \& Harré, N. (2013). Factors associated with distressing electronic harassment and cyberbullying. Computers in Human Behavior, 293), 803-811. Retrieved from http://linkinghub.elsevier.com/retrieve/pii/S0747563212 003135

Green, V. A., Harcourt, S., Mattioni, L., \& Prior, T. (2013). Bullying in New Zealand schools: A final report. Retrieved March 13, 2018, from https://www.victoria.ac.nz/education/pdf/Bullying-in-NZSchools.pdf

He, J., Liu, C., Guo, Y., \& Zhao, L. (2011). Deficits in earlystage face perception in excessive internet users. Cyberpsychology, Behavior, and Social Networking, 14(5), 303-308.

https://doi.org/10.1089/cyber.2009.0333

Jose, P. E., \& Fu, K. Y. (2018). Does receiving malicious texts predict subsequent self-harming behavior among adolescents? Computers in Human Behavior, 89, 328334. https://doi.org/10.1016/J.CHB.2018.08.005

Jose, P. E., Kljakovic, M., Scheib, E., \& Notter, O. (2012). The joint development of traditional bullying and victimization with cyber bullying and victimization in adolescence. Journal of Research on Adolescence, 22(2), 301-309. https://doi.org/10.1111/j.15327795.2011.00764.x

Kautiainen, S., Koivusilta, L., Lintonen, T., Virtanen, S. M., \& Rimpelä, A. (2005). Use of information and communication technology and prevalence of overweight and obesity among adolescents. International Journal of Obesity, 29(8), 925-933. https://doi.org/10.1038/sj.ijo.0802994

Kljakovic, M., Hunt, C., \& Jose, P. E. (2015). Incidence of bullying and victimisation among adolescents in New Zealand. New Zealand Journal of Psychology, 44(2), 57-67. Retrieved from https://www.questia.com/library/journal/1G1436231189/incidence-of-bullying-and-victimisationamong-adolescents 
Livingstone, S. (2013). Online risk, harm and vulnerability: Reflections on the evidence base for child Internet safety policy. ZER: Journal of Communication Studies, 18(35), 13-28. Retrieved from http://eprints.Ise.ac.uk/62278/

Livingstone, S., Carr, J., \& Byrne, J. (2016). One in three: Internet governance and children's rights. Florence. Retrieved from https://www.unicefirc.org/publications/pdf/idp_2016_01.pdf

Livingstone, S., Mascheroni, G., Ólafsson, K., \& Haddon, L. (2014). Children's online risks and opportunities: Comparative findings from EU Kids Online and Net Children Go Mobile. Retrieved from http://eprints.Ise.ac.uk/60513/

Marsh, L., McGee, R., Nada-Raja, S., \& Williams, S. (2010). Brief report: Text bullying and traditional bullying among New Zealand secondary school students. Journal of Adolescence, 33(1), 237-240. https://doi.org/10.1016/j.adolescence.2009.06.001

Orben, A., Dienlin, T., \& Przybylski, A. K. (2019). Social media's enduring effect on adolescent life satisfaction. Proceedings of the National Academy of Sciences of the United States of America, 116(21), 10226-10228. https://doi.org/10.1073/pnas.1902058116

Pacheco, E., \& Melhuish, N. (2017). Teens and "sexting" in New Zealand: Prevalence and attitudes. SSRN Electronic Journal. https://doi.org/10.2139/ssrn.3128598

Pacheco, E., \& Melhuish, N. (2018a). New Zealand teens' digital profile: A factsheet. SSRN Electronic Journal. https://doi.org/10.2139/ssrn.3134305

Pacheco, E., \& Melhuish, N. (2018b). New Zealand teens and digital harm: Seeking and accessing support. SSRN Electronic Journal. https://doi.org/10.2139/ssrn.3208456

Pacheco, E., \& Melhuish, N. (2018c). New Zealand teens and digital harm: Statistical Insights into experiences, impact and response. SSRN Electronic Journal. https://doi.org/10.2139/ssrn.3188608

Pacheco, E., \& Melhuish, N. (2019). Exploring New Zealand children's technology access, use, skills and opportunities. Evidence from Ngā Taiohi Matihiko O Aotearoa - New Zealand Kids Online. SSRN Electronic Journal. https://doi.org/10.2139/ssrn.3461384

Pacheco, E., Melhuish, N., \& Fiske, J. (2019). Digital selfharm: Prevalence, motivations and outcomes for teens who cyberbully themselves. SSRN Electronic Journal. https://doi.org/10.2139/ssrn.3374725

Parkes, A., Sweeting, H., Wight, D., \& Henderson, M. (2013). Do television and electronic games predict children's psychosocial adjustment? Longitudinal research using the UK Millennium Cohort Study. Archives of Disease in Childhood, 98(5), 341-348. https://doi.org/10.1136/archdischild-2011-301508
Rutter, M. (2006). Implications of resilience concepts for scientific understanding. Annals of the New York Academy of Sciences, 1094(1), 1-12.

Smith, P., Mahdavi, J., Carvalho, M., Fisher, S., Russell, S., \& Tippett, N. (2008). Cyberbullying: Its nature and impact in secondary school pupils. Journal of Child Psychology and Psychiatry, 49(4), 376-385. https://doi.org/10.1111/j.1469-7610.2007.01846.x

Smith, S., Ferguson, C., \& Beaver, K. (2018). A longitudinal analysis of shooter games and their relationship with conduct disorder and self-reported delinquency. International Journal of Law and Psychiatry, 58, 48-53. https://doi.org/10.1016/J.IJLP.2018.02.008

Steiner-Fox, H. W., Dutt, S. J., Christiansen, S. J., Newton, H. J., Matika, C. M., Lindsay, C., ... Stronge, S. (2016). Rates of cyberbullying among women and men in New Zealand in 2015. Retrieved February 21, 2017, from https://cdn.auckland.ac.nz/assets/psych/about/ourresearch/nzavs/Feedback Reports/NZAVS-Policy-BriefRate-of-Cyber-Bullying.pdf

Twenge, J. M. (2017). iGen: Why Today's Super-Connected Kids Are Growing Up Less Rebellious, More Tolerant, Less Happy - and Completely Unprepared for Adulthood - and What That Means for the Rest of Us. New York: Simon and Schuster.

Ybarra, M. L., Mitchell, K. J., \& Korchmaros, J. D. (2011). National trends in exposure to and experiences of violence on the Internet among children. Pediatrics, 128(6), e1376-86. https://doi.org/10.1542/peds.2011-0118 

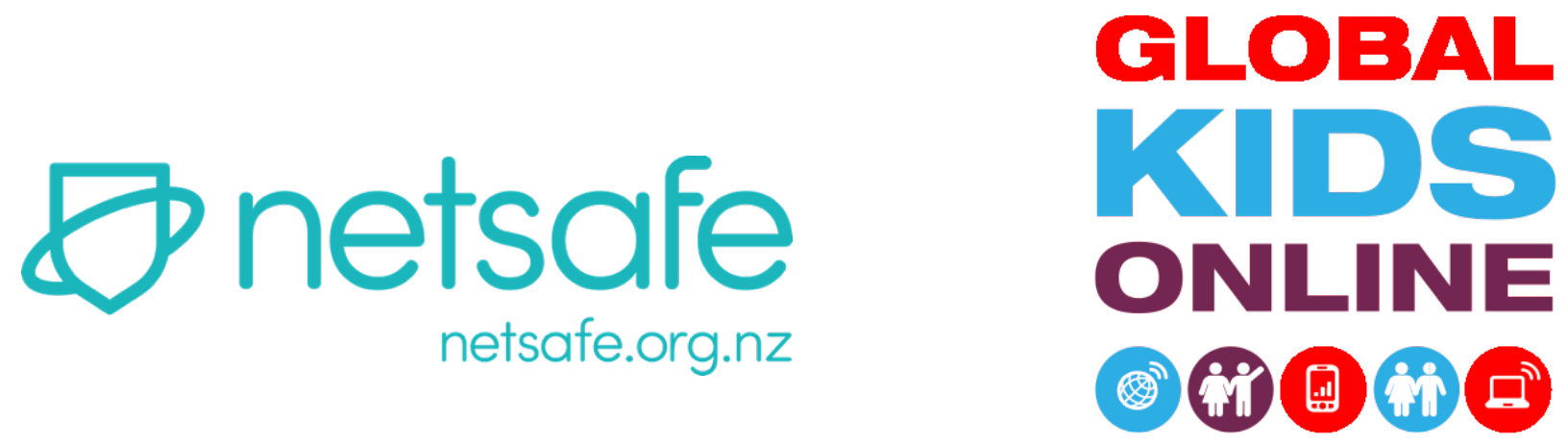

\section{Ngā taiohi matihiko o Aotearoa - New Zealand Kids Online}

New Zealand children's online risks and perceptions of harm. Evidence from Ngā taiohi matihiko o Aotearoa - New Zealand Kids Online

Wellington, New Zealand, February 2020

www.netsafe.org.nz / www.globalkidsonline.net

research@netsafe.org.nz

Retrieved from: https://www.netsafe.org.nz/childrens-online-risks-safety

ISBN: 978-0-473-50589-9

\section{ATTRIBUTION-NONCOMMERCIAL-SHAREALIKE}

(C) $\$(2)$ https://creativecommons.org/licenses/by-nc-sa/4.0/ [English]

BY NC SA https://creativecommons.org/licenses/by-nc-sa/4.O/legalcode.mi [Te Reo Māori] 